\title{
Mecanismos de modalidad interna y externa para expresar probabilidad en el aula de E/LE
}

\author{
INTERNAL AND EXTERNAL MODALITY MECHANISMS FOR \\ THE EXPRESSION OF PROBABILITY IN THE SPANISH SL CLASSROOM

\section{Lorena Camacho Guardado} \\ University of Texas at Dallas \\ RESUMEN
}

La expresión de la probabilidad en español es una de las cuestiones que mayores problemas presenta en la enseñanza de E/LE, pues contamos con numerosos mecanismos de modalidad interna y externa que, además, o bien seleccionan un modo o bien pueden seleccionar tanto indicativo como aproximativo y/o subjuntivo. Parte del problema radica en la incongruencia terminológica de las formas del sistema verbal español, así como en las poco operativas descripciones que siguen el modelo tradicional, que se limitan a clasificar dichos mecanismos según sus esquemas sintácticos de subordinación y qué modo selecciona cada uno de ellos, y dejan de lado cualquier valor pragmático de atenuación y/o aproximación de algunos de estos.

PALABRAS CLAVE: Probabilidad, atenuación, aproximación, selección modal, gramática cognitiva

\section{ABSTRACT}

The expression of probability in Spanish is one of the most problematic issues in the Spanish SL classroom, because it has numerous internal and external modality mechanisms that, in addition, can select one mood or can select indicative, approximative and/or subjunctive. The problem lies in the tenses terminological incongruity, as well as the little operative descriptions that follow the traditional 
model, classifying those mechanisms depending on their syntactic structure and which mood they select, as well as avoiding any attenuation and/or approximation pragmatic value.

KEYWORDS: Probability, attenuation, approximation, mood selection, cognitive grammar

\section{LA EXPRESIÓN DE LA PROBABILIDAD EN ESPAÑOL}

Para expresar lo que no se sabe o la falta de compromiso con la verdad de lo que se enuncia, disponemos de una gran variedad de medios de expresión: verbos cognitivos (creer, pensar, suponer, dudar, parecer...), verbos modales (poder, deber (de), tener que, haber de...), sustantivos (tengo la duda de que/si, existe la posibilidad de que...), adjetivos (es posible/probable que...), adverbios (quizá, tal vez, posiblemente, probablemente...), así como

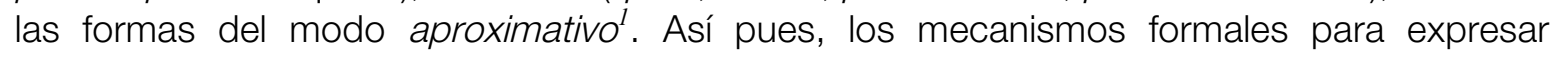
probabilidad son tanto de modalidad externa como interna.

Si en la modalidad interna la actitud del hablante queda reflejada mediante recursos gramaticales como el modo, en un enunciado de modalidad externa aparecen unidades léxicas (verbo, adjetivo, sustantivo y adverbio) cuyo significado alude a una actitud psicológica o perspectiva modal del hablante, lo que indica que este es capaz de objetivar su actitud de alguna manera haciéndola explícita (Carbonero Cano, 1997: 67).

Entre las dificultades, a la hora de llevar al aula de E/LE la expresión de la probabilidad, nos encontramos con que algunos de estos mecanismos seleccionan un modo ${ }^{2}$ (es posible que...), mientras que otros pueden seleccionar tanto indicativo como aproximativo y/o subjuntivo (quizá, probablemente, posiblemente, seguramente...). Para explicar la selección modal en esta función comunicativa, se suele dar una constante mezcla de criterios de tipo semántico, sintáctico y pragmático que, como consecuencia, resulta en descripciones poco operativas (Ruiz Campillo, 1998: 91): que un morfema no tiene significado alguno (justificación sintáctica), creer que el significado puede ser descrito independientemente de las restricciones impuestas por la estructura de la información (justificación semántica) o seleccionar la perspectiva exclusiva que en cada caso convenga, despreciando la solución unitaria del problema (justificación de la mezcla de criterios).

Asimismo, es necesario tener en cuenta el valor pragmático (no sólo semántico) de las distintas formas para expresar probabilidad en español, pues esto explicaría por qué algunas -como a lo mejor, igual o lo mismo- no pueden seleccionar subjuntivo, y es que funcionan como atenuantes pragmáticos de la responsabilidad, pasando, por tanto, a expresar máxima

\footnotetext{
${ }^{1}$ También llamado condicionado o potencial.

${ }^{2}$ Tanto las tradicionales como las de E/LE solo distinguen entre indicativo y subjuntivo.
} 
probabilidad o, incluso, conocimiento de la veracidad o no de aquello sobre lo que el hablante hipotetiza, como es el caso de creer que, que además de expresar opinión puede tener un valor real de afirmación.

Por otro lado, algunas gramáticas y métodos de E/LE han intentado proponer una escala de probabilidad atendiendo al mayor o menor grado de seguridad que el hablante tiene sobre el hecho que refiere. Con todo, esto no es posible -incluso intentando tener en cuenta una virtualidad semántica y otra pragmática de cada uno de los mecanismos para expresar dicha función comunicativa-, debido tanto a la subjetividad emisiva como a la receptiva, ya que es necesario tener en cuenta, por un lado, la intencionalidad del hablante y, por otro, la interpretación del interlocutor según el sentido del discurso y otros componentes paralingüísticos o extralingüísticos. Así pues, es necesario diseñar métodos didácticos que muestren de forma gradual los criterios semántico, sintáctico y pragmático para, posteriormente, revelar que estos están conectados.

\subsection{Mecanismos de modalidad interna}

El metalenguaje empleado, tanto en las gramáticas tradicionales como en las de E/LE ${ }^{3}$, en la descripción del funcionamiento del sistema verbal español muestra incoherencias:

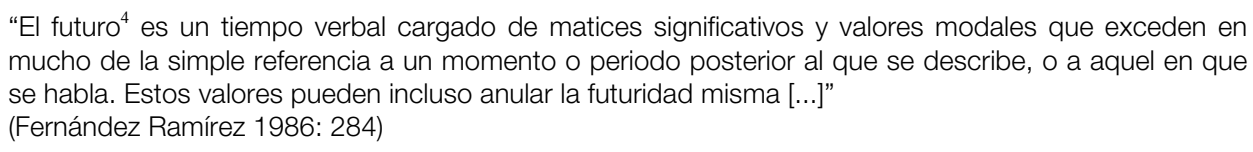

Si el nombre muestra incongruencias, la regla misma resulta incongruente, ya que conocemos las cosas a través de los nombres. Si un nombre contradice el objeto, ¿por qué darle ese nombre? La respuesta, como bien dicen Ruiz Campillo (1998: 11) y Castañeda Castro (2004a: 83), está en el hecho de que tal regla no es operativa y que una descripción coherente del sistema verbal puede beneficiarse de las distinciones que la pragmática permite establecer.

Algo a tener muy en cuenta es que el verbo no tiene por qué expresar en cada uno de sus contextos de uso las categorías que posee. Es decir, no está estrictamente unido a una única noción -como la de tiempo-, pudiendo transmitir distintos mensajes a los supuestos en primera instancia. Esto se debe a una mayor versatilidad del sistema (Real Espinosa, 2005: 2). El sistema verbal español permite cancelar el valor temporal, generando una interpretación modal del morfema. Por lo tanto, el morfema -rá puede expresar temporalidad o modalidad según se cancele o no un valor u otro del morfema en el contexto en el que aparezca. Así, el

\footnotetext{
${ }^{3}$ Estas siguen la terminología de las gramáticas tradicionales.

${ }^{4}$ Estamos de acuerdo con Matte Bon en que el apelativo futuro parece poco adecuado ya que lleva a pensar en el futuro cronológico, cuando en realidad se refiere a este tan sólo en algunos de sus empleos. Además, con el nombre de futuro se cae en el error de creer que, para expresar futuridad, hay que emplear esta forma (error frecuente en muchos manuales de español para extranjeros, en los que se presentan diálogos enteros en esta forma, con muchos usos que resultan raros o agramaticales).
} 
sistema evita tener que crear un morfema nuevo y específico para cada expresión o el empleo de una estructura sintáctica más compleja. Pero esto no es algo exclusivo del español, ya que cualquier lengua suele inclinarse por crear mensajes comprensibles con el menor número posible de elementos gramaticales. Con todo, es necesario señalar que no hay que entender esta multiplicidad de valores solo como economía del lenguaje, sino como "riqueza de matices modales", dotando a la lengua de una mayor capacidad expresiva con el mismo número de formas (Real Espinosa, 2005: 3).

Veamos algunos ejemplos de dicha incongruencia terminológica (solo atendiendo a la temporalidad):

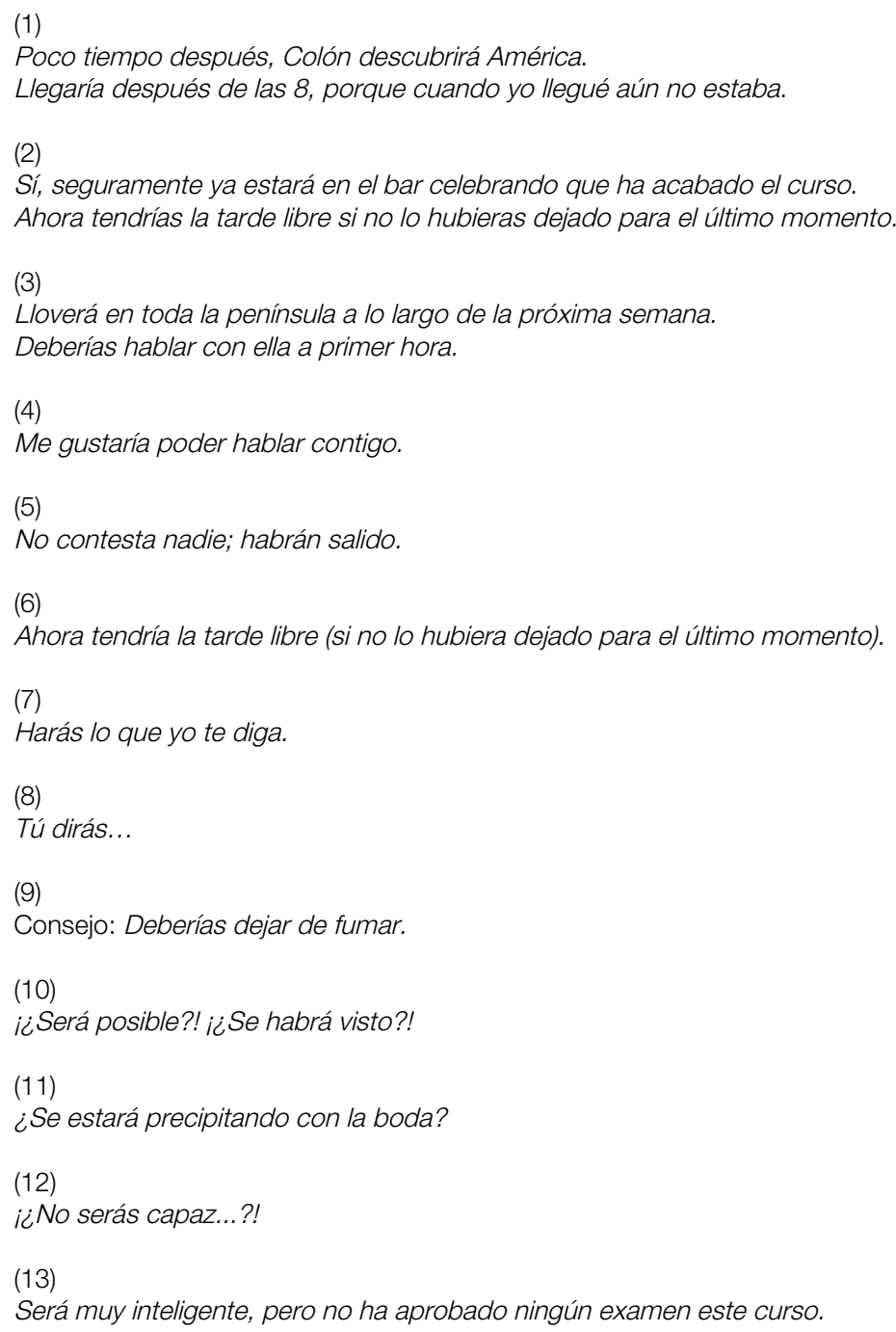


Como vemos en los ejemplos, el futuro no es futuro (Ruiz Campillo, 2006). Y es que dichas formas, al igual que las del "condicional", poseen valores tanto temporales-pasado (1), presente (2) y futuro (3)- como modales ${ }^{5}$-deseo (4), probabilidad (5), hipótesis (6), mandato (7), cortesía (8), consejo (9), sorpresa (10), duda (11) y desafío (12).

Las formas de "futuro", así como las del "condicional", expresan algo no realizado. Estas se diferencian del presente y de los pasados porque expresan un enunciado que no puede interpretarse como verdadero o falso al igual que ocurre con las formas del indicativo, ya que, en el caso de estas formas verbales, lo que tenemos es la opinión o la valoración aproximada que de un hecho emite el hablante. Por lo tanto, el interlocutor no debe interpretar el mensaje de aquel como algo que se va a producir, sino como la predicción o la aproximación sobre el hecho mismo.

En los ejemplos de futuridad (3), deseo (4), probabilidad (5), hipótesis (6), estamos claramente ante aproximaciones o valoraciones aproximadas del hecho por parte del hablante. En cuanto al valor de mandato (7), Gómez Torrego (1999: 3348) señala que habría una estrecha relación entre el campo semántico de la obligación y el de la duda, lo que explicaría la generalizada confusión en el uso de deber y deber de, así como los valores tanto epistémicos como deónticos de cantaré y habré cantado, tener que, haber que, haber de y poder + infinitivo. El autor ofrece como posible respuesta ${ }^{6}$ el hecho de que en toda "probabilidad" se esconde una "obligación", ya que, cuando el hablante expresa una hipótesis, lo hace obligado por las circunstancias externas o pragmáticas, es decir, se da una situación de "causa"; y si, a pesar de todo, mantiene un margen de duda es porque también interactúa la existencia de una "condición"?.

Esta relación semántica entre la "probabilidad" y la "obligación" explica los contextos de desafío (12), que no es más que una forma de mandato, de cortesía (8) -aproximación sobre el hecho mismo- y de consejo (9) -valoración aproximada del hecho por parte del hablante. De la misma forma que en español se emplean las perífrasis que expresan orden u obligación para la cortesía y el dar consejos, el mal llamado futuro también puede hacerlo.

En cuanto al llamado futuro concesivo, es necesario señalar que lo que realmente expresa dicha forma es probabilidad/posibilidad. Y es que en (13) será no equivaldría a aunque sea, sino a es posible que sea, ya que es la conjunción pero la que aporta ese valor adversativo (no ya concesivo). La diferencia con es posible que sea es clara: será funciona como atenuante

\footnotetext{
${ }^{5}$ Cantaré puede expresar probabilidad, mandato, cortesía, sorpresa, duda y desafío; mientras que cantaría tiene valores modales de deseo, probabilidad, hipótesis, cortesía, consejo y duda.

${ }^{6}$ Llega a esta conclusión buscando una explicación a la identificación entre deber y deber de, si bien esto es aplicable a las formas de modalidad deóntica y epistémica anteriormente citadas.

${ }^{7}$ De ahí que se vacile muchas veces en contextos del tipo Han pasado ya tres horas, por lo que el autobús debe (de) ir lejos, en los que la situación "causa" («porque han pasado tres horas») obliga a que el autobús vaya lejos; pero la situación "condición" («si es que no ha ocurrido algo") mantiene al hablante en una actitud de duda.
} 
pragmático de la responsabilidad, mientras que el mecanismo que selecciona subjuntivo evidenciaría que el hablante estaría cuestionando -o considerando mínima su posibilidad- el hecho de ser inteligente.

\subsection{Mecanismos de modalidad externa}

El significado de las unidades léxicas empleadas en este tipo de enunciados manifiesta explícitamente una actitud psicológica o perspectiva modal determinada del hablante.

En cuanto a las perífrasis verbales, destaca el hecho de que la mayoría de los gramáticos tradicionales no se plantea que las obligativas pueden igualmente expresar una modalidad epistémica de aproximación, no solo radical o deóntica -si bien en las de E/LE si aparecen como mecanismos de modalidad externa para expresar probabilidad. Gómez Torrego es el único que, preguntándose por la tan extendida confusión mencionada anteriormente entre deber/deber de + infinitivo, señala la estrecha relación entre el campo semántico de la obligación y el de la duda, ofreciendo como respuesta el hecho de que en toda "probabilidad" se esconde una "obligación" debido a circunstancias externas o pragmáticas, de ahí que se vacile muchas veces en este tipo de contextos. Esto explicaría que tener que y deber presenten usos con valores aproximativos y que las formas cantaré, habré cantado, cantaría y habría cantado (originalmente perífrasis obligativas en presente y en pasado) tengan cabida en ambos campos. Ese es, precisamente, el rasgo que permite que en español y en multitud de lenguas se empleen dichas perífrasis obligativas para hacer hipótesis.

Con respecto a los enunciados de modalidad externa que emplean verbos cognitivos y modales, así como sustantivos y adjetivos, no se dispone de suficientes estudios y, los que se han encontrado, se limitan a clasificarlos según sus esquemas sintácticos de subordinación y qué modo selecciona cada una de estas unidades léxicas. Sin embargo, hay intentos de clasificaciones semánticas, que facilitarían la comprensión del funcionamiento real de estos verbos, si bien estos se quedan en simples propuestas sin explicación alguna, como la de la Nueva Gramática de la Lengua Española (2009: 1773), en la que se señala que los verbos imaginarse, figurarse y suponer serían de percepción mental; o propuestas que reconocen la dificultad de explicación para todos los contextos, como la de Demonte (1977) que, aunque cree posible establecer diferentes clases semánticas de predicado (presuposición e implicación) con respecto a la subordinada, señala la imposibilidad de basarse exclusivamente en esas propiedades presuposicionales e implicativas por la necesidad de tener en cuenta factores modales y temporales de los enunciados.

En cuanto al adverbio, destaca la ausencia en las gramáticas tradicionales de los adverbios seguramente o aparentemente para expresar probabilidad, así como probablemente o posiblemente, reconociendo la mayoría solo quizá, tal vez y acaso. Sin embargo, en las gramáticas de E/LE sí hay cabida para más adverbios y locuciones adverbiales como seguramente, probablemente, posiblemente, igual, a lo mejor, lo mismo... 
Es necesario destacar el carácter de atenuante pragmático de la responsabilidad que tienen a lo mejor (Briz, 1995), lo mismo e igual, ya que esto explicaría su frecuente uso en la oralidad incluso en contextos no propiamente de duda, hecho que debería hacernos reflexionar a los docentes sobre su grado de probabilidad, pues no siempre expresaría la mínima posibilidad como se ha venido diciendo hasta ahora. Ese carácter lenitivo sería igualmente aplicable a verbos como creer o pensar, cuyo uso junto a formas verbales en modo indicativo respondería a que el hablante reconoce la subordinada que rigen como verdadera o como un hecho. Al igual que a lo mejor, serían atenuantes pragmáticos de la responsabilidad, pero en distinto grado, según el contexto.

\section{LOS MODOSDEL ESPAÑOL}

\subsection{Modo y modalidad}

La categoría de la modalidad es reconocida en todas las lenguas. Sin embargo, no todas la expresan en la morfología verbal. Bien es cierto que el modo verbal juega un papel importantísimo en la constitución de la modalidad lingüística, lo que ha llevado en multitud de ocasiones a considerarlos sinónimos, sin embargo el modo es una categoría gramatical (o inflexional) muy distinta de otra (sobre todo de nivel) discursiva que es la modalidad lingüística (Zamorano Aguilar, 2001: 187).

Según la prescripción normativa, esa categoría se identifica como actitudes o posiciones del hablante acerca de la enunciación, sea con respecto a la verdad del contenido de la proposición que manifiestan, sea con respecto a la actitud de los participantes en el acto de la misma, y se realiza en el sistema gramatical del modo verbal.

En toda oración hay que distinguir entre el dictum, correlato del proceso que constituye la representación, y el modus, la expresión de la modalidad, correlativa a la operación de formulación del dictum por parte del sujeto hablante. Es necesario diferenciar la posición del hablante cuando este no tiene certeza sobre la realidad de lo aseverado (matización de la modalidad lógica de la proposición de carácter epistémico) y cuando formula un mandato o un deseo (matización de la modalidad lógica de la proposición de tipo deóntico).

La tradición europea, siguiendo a Jakobson, establece una doble distinción de modalidad:

- modalidad de la enunciación

- modalidad del enunciado

La "modalidad del enunciado" simplemente caracteriza la manera en que el hablante sitúa la proposición con respecto a la verdad (posibilidad, certidumbre, imposibilidad); de modo que en ella no intervienen factores exteriores al signo lingüístico, por lo que solo se produce una atenuación de la predicación. 
En la "modalidad de la enunciación", existen factores que conciernen a la forma de comunicación entre el hablante y el oyente (por ejemplo, mandato o pregunta frente a declaración); dicho de otro modo, intervienen componentes del proceso de la comunicación lingüística distintos del enunciado en sí: por ejemplo, en un mandato quedan implicados el hablante y el oyente.

Emilio Ridruejo (1999: 3213) afirma que esta distinción puede ser útil para el análisis de ciertas categorías gramaticales cuyos límites se adaptan exclusivamente a uno de los dos tipos de modalidad. Pone como ejemplo la interrogación en español, que constituye una "modalidad de la enunciación" frente a la declaración; ejemplo con el que Ruiz Campillo disiente, como veremos más adelante. No obstante, con relativa frecuencia, encontramos que una determinada categoría lingüística modal implica tanto a la enunciación como al enunciado ${ }^{8}$.

Pero para una lengua como el español, Ridruejo cree que es más ventajosa la distinción entre "modalidad epistémica" y "modalidad deóntica", porque existen categorías gramaticales que se diferencian de acuerdo con cada tipo de modalidad.

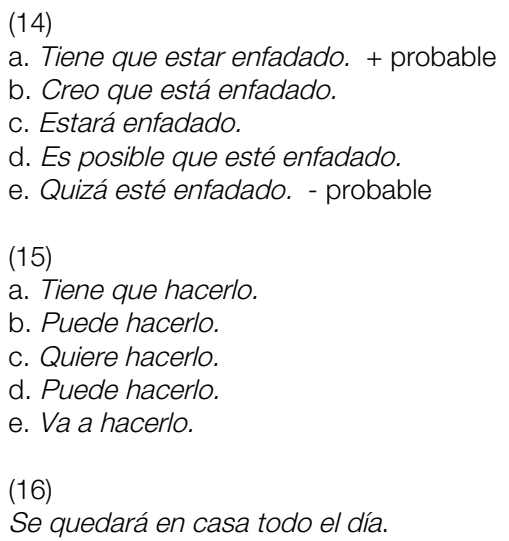

La "modalidad epistémica" (14) se refiere a nociones que guardan relación con la posibilidad o con la necesidad, la evidencia (sobre todo a través de los sentidos) o con lo oído o lo expresado por otros (Martín Zorraquino 1998: 27) y expresa la evaluación que hace el hablante sobre el grado de probabilidad que tiene del enunciado con respecto al mundo que le rodea. Mediante

\footnotetext{
8 Mientras que mediante la categoría de la modalidad se intenta analizar y describir ciertos elementos significativos de los enunciados, la teoría de los actos de habla, para dar cuenta de las finalidades con que se emplean los enunciados, distingue entre el acto "locutivo" (con el que el hablante simplemente "dice algo") y el acto "ilocutivo" (con el que el hablante realiza alguna actividad distinta de la mera comunicación). Searle (1975/1979) habla de cinco categorías básicas de actos ilocutivos: asertivos, directivos, comisivos, declarativos y expresivos. De entre ellos, claramente cabe identificar las llamadas modalidades deónticas con los actos comisivos y directivos, mientras que los actos asertivos incluyen diferentes formas de modalidad epistémica. (Ridruejo, 1999: 3213, nota 4).
} 
diversos recursos lingüísticos tales como adverbios, adjetivos, verbos modales y variación en el modo del verbo, podemos transmitir esos grados de probabilidad.

La "modalidad deóntica" (15) describe condiciones, bien en el agente de la oración, bien directamente en el hablante (Lyons 1980: 754 y ss.), como son la obligación (15a), el permiso (15b), el deseo (15c), la habilidad (15d) o la intención (15e) de hacer algo. Este tipo de modalidad puede recibir su expresión mediante la entonación, la sintaxis, la variación del modo verbal.

La "modalidad deóntica" implica también una determinada "modalización epistémica", cuando la proposición a la que se refieren tiene carácter no factivo, ya que la expresión de un mandato, por ejemplo, supone desconocimiento o incertidumbre por parte del hablante con respecto al cumplimiento del contenido del mismo (Ridruejo 1999: 3215). Además, como podemos ver, cada tipo de modalidad deóntica en los anteriores ejemplos aparece expresado mediante un verbo auxiliar en presente que, sustituyéndolo por "futuro" o "condicional", puede expresar a su vez distintas gradaciones de posibilidad.

Igualmente, una misma construcción puede transmitir ambas modalidades sin producir ambigüedad alguna: por ejemplo, el mal llamado "futuro imperfecto" en español se emplea para transmitir tanto "modalidad deóntica" de mandato como "modalidad epistémica" de incertidumbre (posibilidad). Así, en (16) se quedará no se sabe si es porque lo han castigado o porque tenía cosas que hacer.

Los contenidos de modalidad epistémica (14) son considerados subjetivos puesto que reflejan la opinión del hablante; los de modalidad deóntica (15), serían objetivos porque indican la relación entre un participante del evento y el evento mismo (González Vázquez, 1998: 2). Sin embargo, Lyons (1977: 729-741) diferencia dos tipos de modalidad epistémica: objetiva y subjetiva. Con la primera transmitimos, en realidad, una aseveración, ya que presentamos la existencia de una posibilidad independientemente de nuestra opinión. En cambio, con la modalidad epistémica subjetiva manifestamos nuestra creencia en que algo pueda ser igualmente cierto o no, por tanto nuestra duda, ya que no excluimos ninguna de las posibilidades.

Según Stephany (1995: 112), los significados epistémicos -que forman parte del discurso narrativo y argumentativo, así como del razonamiento- se adquieren tardíamente en una L2/LE puesto que exigen un mayor grado de competencia lingüística y comunicativa por parte del aprendiente.

Como se ha podido ver en los ejemplos, los mecanismos formales para expresar una misma modalidad (la de la probabilidad, que es la que aquí nos ocupa) son muy diversos. Es por ello que se deben clasificar, atendiendo a las formas del significante modal: modalidad externa e interna. Hablamos de modalidad externa "cuando en la construcción del enunciado aparecen expresamente unidades léxicas (verbo, adjetivo, sustantivo y adverbio) de significado modal, 
es decir, que el propio significado de tales unidades alude a una actitud psicológica o perspectiva modal del hablante, lo que indica que este es capaz de objetivar su actitud de alguna manera haciéndola explícita. En la modalidad interna esto no ocurre y la actitud del hablante queda reflejada mediante recursos fónicos (como la entonación) y/o recursos gramaticales, entre los cuales cobran especial relevancia el modo y el tiempo verbal, además de ciertas construcciones sintácticas" (Carbonero Cano, 1997: 67 y ss.).

\subsection{Tres modos verbales}

Teniendo en cuenta la "modalidad de los enunciados", y siguiendo a Ruiz Campillo9, solo cabe hablar de aserción (indicativo) frente a no-aserción (subjuntivo). Sin embargo, se nos presenta un problema al utilizar el término "aserción", propuesto por muchos, para dar cuenta de la modalidad en (17), ya que la idea de "dar por cierta alguna cosa" no nos permitiría incluir formas que carecen de carácter veritativo:

(17)

No contesta al teléfono; estará ocupado.

A estas horas ya habrá llegado.

Yo lo haría si pudiera.

Se lo habría dicho, pero no me dejó.

Ejemplos como estos han llevado a algunos gramáticos a hacer una reestructuración del sistema verbal español separando muy acertadamente las formas del "futuro" y "condicional" de los modos tradicionales:

\begin{tabular}{|c|c|c|}
\hline Alarcos & Matte Bon & Ruiz Campillo \\
\hline $\begin{array}{l}\text { Indicativo: "designa la no } \\
\text { ficción de lo denotado por la } \\
\text { raíz del verbo, esto es, todo } \\
\text { lo que el hablante estima real } \\
\text { o cuya realidad no se } \\
\text { cuestiona". }\end{array}$ & $\begin{array}{l}\text { Modo Informativo: es el modo "que } \\
\text { mejor se presta para dar } \\
\text { informaciones nuevas, que todavía ni } \\
\text { se han hecho explícitas ni los } \\
\text { interlocutores pueden suponer, } \\
\text { sobre un sujeto gramatical del que se } \\
\text { quiera hablar." }\end{array}$ & $\begin{array}{l}\text { Declaración: "lo que un } \\
\text { sujeto sabe o piensa } \\
\text { sobre el mundo" } \\
\text { a) Positiva (Indicativo) } \\
\text { b) Suponiendo } \\
\text { (Predictivo) }\end{array}$ \\
\hline $\begin{array}{l}\text { Condicionado: "designa los } \\
\text { hechos aludidos por la raíz } \\
\text { verbal como sometidos a } \\
\text { valores varios que lo harán } \\
\text { posibles". }\end{array}$ & $\begin{array}{l}\text { Modo Virtual: informa "sobre cosas } \\
\text { virtuales o consideradas como tales } \\
\text { por el enunciador en el momento de } \\
\text { la enunciación." }\end{array}$ & \\
\hline $\begin{array}{l}\text { Subjuntivo: "señala el } \\
\text { carácter ficticio, no real, de lo } \\
\text { que denota el significado de } \\
\text { la raíz verbal". }\end{array}$ & $\begin{array}{l}\text { Modo No informativo: "se distingue } \\
\text { de todos los demás tiempos del } \\
\text { español por no presentar } \\
\text { informaciones nuevas. El enunciador }\end{array}$ & $\begin{array}{l}\text { No declaración: } \\
\text { "mencionar sin declarar" } \\
\text { (Subjuntivo) }\end{array}$ \\
\hline
\end{tabular}

\footnotetext{
${ }^{9}$ No está de acuerdo con Alarcos en la existencia de las modalidades de interrogación y apelación.
} 


\begin{tabular}{|l|l|l|}
\hline pone los verbos en subjuntivo \\
cuando solo quiere referirse a la \\
relación entre sujeto y predicado, sin \\
dar informaciones sobre el sujeto del \\
verbo."
\end{tabular}

Tabla 1. El modo según Alarcos, Matte Bon y Ruiz Campillo

Matte Bon (1992) mejoró la capacidad explicativa de la clasificación modal suponiendo valores más generales y operativos en cada "modo", poniendo en juego los factores discursivos que intervienen en la selección modal, lo que demuestra un avance notable en algunos casos. Sus planteamientos se distancian del tradicional binomio lengua/realidad, en el que se basa la mayor parte de las explicaciones al uso del problema. La aportación esencial de Matte Bon a una descripción del cómo y por qué usamos el subjuntivo fue tener, por tanto, en cuenta el contexto discursivo dentro del que se enmarca una comunicación determinada, en la que los interlocutores se intercambian informaciones o las dan por sabidas.

Ruiz Campillo (1998) señala que el concepto de información como valor asociado a la selección modal "se siente más bien como una de las varias posibles consecuencias interpretativas de algo más básico que realmente pueda ser considerado un acto del hablante capaz de transmitirla" y que él identifica como declaración (poner de relieve un estado de cosas). El modo, pues, es una pura representación de actos que el hablante manipula a su conveniencia. Aunque reduce el valor del modo a declaración (indicativo) y no-declaración (subjuntivo), afirma que existen precisiones con respecto al diferente "modo" en que es posible declarar o evitar una declaración. Aun concediendo el valor declarativo a "futuro" y "condicional", reconoce que es evidente el carácter modal del contraste "Está en la cárcel/Estará en la cárcel" o "Dijo que sí/Diría que sí", por lo que defiende la existencia de un modo aproximativo/predictivo que es el que nos parece más adecuado para la enseñanza de español como lengua extranjera.

Sin embargo, en cuanto a la expresión de la probabilidad, las nociones de declaración/nodeclaración no terminan de explicar el hecho de que haya adverbios o locuciones adverbiales que seleccionen los tres modos (probablemente, posiblemente, seguramente...) y otros (a lo mejor, lo mismo, igual) que no puedan seleccionar subjuntivo.

Con respecto a esto, es necesario señalar que Antonio M. Bañón Hernández -en su artículo "Apuntes para el análisis sintáctico-semántico de la locución a lo mejor en español hablado", estudia tanto los modalizadores aléticos (que hacen referencia a la representación lingüística de la necesidad, la contingencia, la posibilidad e imposibilidad) como los modalizadores epistémicos (que aluden a la certidumbre, la incertidumbre, la probabilidad y la improbabilidad) 
desde las perspectivas morfo-fonética, sintáctico-semántica y pragmático-textual, si bien la primera la deja para futuras investigaciones ${ }^{10}$.

En cuanto a la perspectiva sintáctico-semántica, y citando a García de Dini (1980), señala que a lo mejor no es una muestra de duda, sino que transmite la información como segura; es decir, que funciona como locución-signo que el hablante emite cuando quiere convencer a su interlocutor de la seguridad o realidad de su juicio al connotar su opinión con ésta, transmitiendo así una fuerza probable-segura, hecho que justificaría su uso con indicativo (1999: 138). Por tanto, semánticamente se acercaría más a la certeza que a la duda y sería un claro ejemplo de lo que Klaus Heger denomina "posibilidad realizada".

En el discurso oral, y desde una perspectiva pragmático-textual, se utilizaría para tranquilizar al interlocutor o para exponer informaciones de manera indirecta que le puedan resultar graves, aunque el hablante esté convencido de su veracidad; por tanto, responde a un intento por ser diplomático o cortés en el acto comunicativo y su función básica es la de atenuante pragmático de la responsabilidad del hablante en relación con la verdad de lo dicho (Briz 1995: 111).

Así pues, su característica de atenuante haría que dicha locución adverbial cambiara su posición en una supuesta escala de la probabilidad, no expresando mínima posibilidad como se venía afirmando en algunas gramáticas de E/LE hasta ahora.

\subsection{Nuevos valores centrales}

Si nos detenemos en los siguientes enunciados, podemos ver claramente la diferencia de modalidad existente entre ellos:
(18)
a. Está en casa
b. Estará en casa
c. Es posible que esté en casa

(19)
a. Volvió a casa
b. Volvería a casa
c. Puede que volviera a casa

Como ya se ha dicho, las formas de "futuro" y del "condicional" expresan algo no realizado y se diferencian del presente y de los pasados porque expresan enunciados que no pueden interpretarse como verdaderos o falsos, al igual que ocurre con las formas del indicativo, ya que lo que tenemos es la opinión o la valoración aproximada que de un hecho emite el

${ }^{10}$ El autor se plantea cuestiones como su origen, si este tiene que ver con la frecuencia de uso en contextos discursivos similares y por qué una estructura comparativa puede expresar otro sentido de duda. Esta última pregunta es interesante, puesto que otras estructuras comparativas como igual o mismo también se emplean en la oralidad para expresar duda. 
hablante. Por lo tanto, el interlocutor no debe interpretar el mensaje de aquel como algo que se va a producir, sino como la predicción o la aproximación sobre el hecho mismo.

Podemos comprobar que los ejemplos de (18a) y (19a) no son más que una información positiva sobre el presente y el pasado; los de (18b) y (19b) lo hacen de una forma aproximativa. Es decir, son informaciones sobre lo que contemplamos dentro de nuestra realidad o contexto inmediato: lo que conocemos -porque es un hecho- (indicativo) o lo que desconocemos, pero consideramos posible en él (aproximativo). ¿Qué diferencian estas informaciones de los ejemplos de (18c) y (19c)? El subjuntivo no informa sobre hechos (evidentes o probables), sino que expresa ideas que el hablante no considera como parte de su contexto inmediato (porque las rechaza, las cuestiona o considera mínima su posibilidad).

Mediante el siguiente dibujo que diseñamos basándonos en los estudios realizados por Langacker (1991) y Castañeda Castro (2004b) - podemos explicar de forma significativa el sistema modal español, dejando de lado cualquier criterio temporal como valor exclusivo de cada una de sus formas:

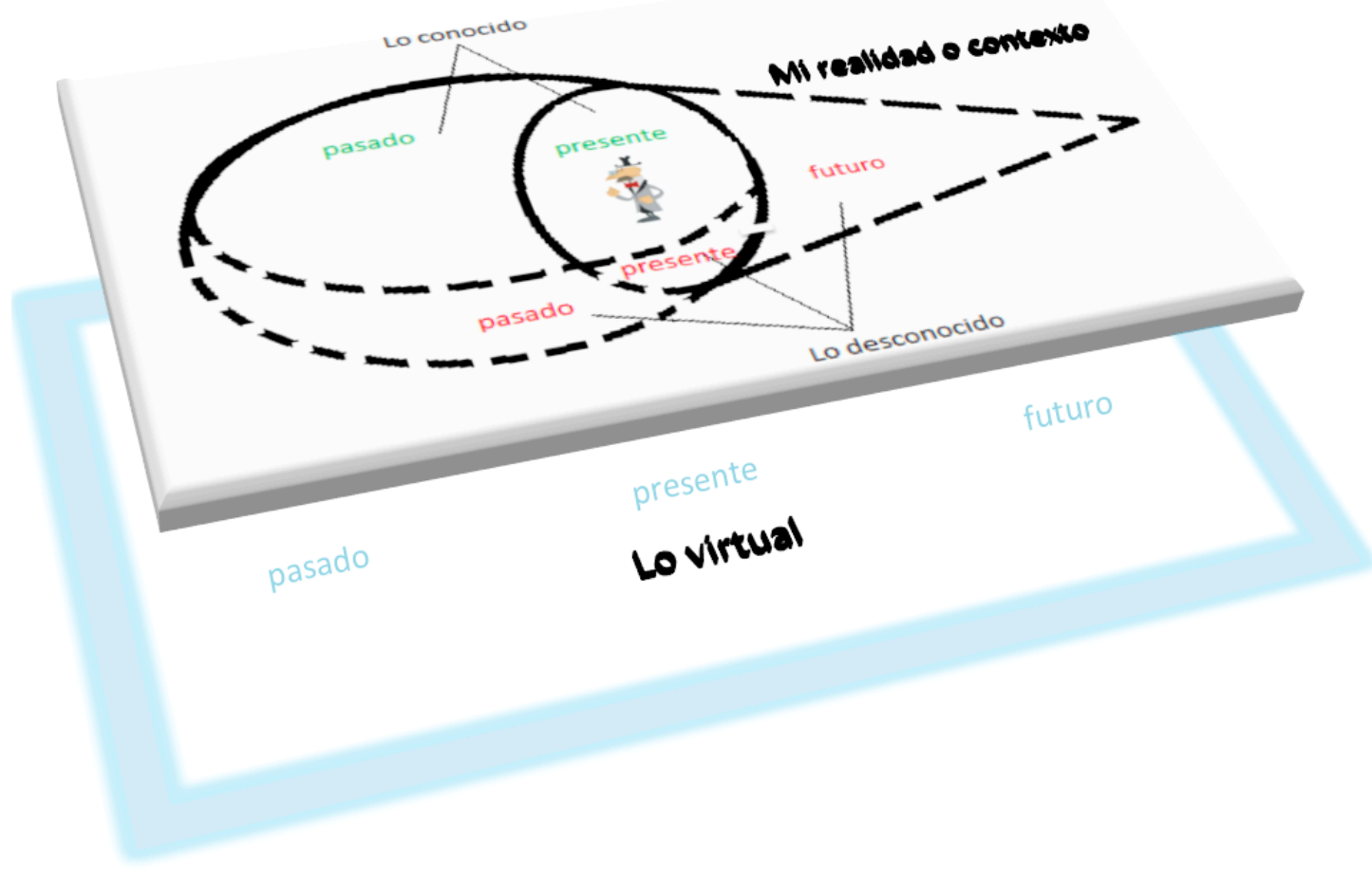

Figura 1. Nuevos valores centrales para los modos del español 
El dibujo, a diferencia del propuesto por Castañeda ${ }^{11}$ (2004b: 56), se compone de dos planos o niveles: el de mi mundo o contexto inmediato y el plano de lo virtual. En el primero, estaría lo que conozco -porque es un hecho o considero que lo es- y lo que desconozco -pero considero que puede ser un hecho- en pasado, presente o futuro. Las líneas discontinuas hacen referencia a lo desconocido, mientras que las continuas se refieren a lo que conoce el hablante. En el plano virtual, estaría todo aquello que el hablante rechaza, cuestiona, considera mínima su posibilidad o no existe aún para él.

Así pues, el sistema verbal quedaría de la siguiente forma:

\begin{tabular}{|c|c|c|c|c|}
\hline Lo conocido & había cantado & canté/cantaba & he cantado & canto \\
\hline Lo desconocido & habría cantado & cantaría & habré cantado & cantaré \\
\hline Lo virtual & $\begin{array}{c}\text { hubiera/hubiese } \\
\text { cantado }\end{array}$ & cantara/cantase & haya cantado & cante \\
\hline
\end{tabular}

Tabla 2. Reestructuración del sistema verbal español

\subsection{El modo en mecanismos de modalidad externa}

La selección modal para expresar probabilidad depende no sólo de factores perceptivos o psicológicos, sino de procesos cognitivos del hablante, por lo que urge la necesidad de actualizar el enfoque comunicativo en el ámbito del español como lengua extranjera. Debemos pasar, pues, de una teoría del lenguaje basada en las formas, a una teoría basada en el significado, ya que sólo así podremos instruir al aprendiente no sobre cuándo debe usar presente de indicativo, presente de aproximativo o presente de subjuntivo junto a mecanismos de modalidad externa como quizá, probablemente, posiblemente, seguramente..., sino ayudarle a comprender dicho significado, para que pueda escoger las formas que mejor representen su pensamiento y que logre autonomía en su proceso de aprendizaje.

Antes de aplicar los valores centrales propuestos en el apartado anterior, es necesario detenerse en la secuenciación de los mecanismos para expresar probabilidad en español. Ante todo, la primera necesidad es la descripción coherente del sistema verbal para poder, así, hacer más fácil el proceso de enseñanza/aprendizaje no ya de la expresión de la probabilidad, sino del español como L2/LE. El "futuro" y el "condicional" (en sus formas simple y compuesta)

${ }^{11}$ Castañeda Castro habla en la figura 1 de espacios en el mundo representado por el sujeto conceptualizador. 
no pueden ser considerados como tiempos sino como un modo independiente y particular: el modo aproximativo. Dichas formas deben presentarse por primera vez en el aula en un nivel A2+ pues, si se hace más tardíamente, el aprendiente no las adquirirá con sus valores modales, sino temporales.

En cuanto a los mecanismos de modalidad externa, los significados epistémicos se adquieren tardíamente en una L2/LE, y es que en los niveles elementales el conocimiento de los aprendientes es léxico; es decir, poseen un bajo grado de gramaticalización de su competencia. Así, recurren en primer lugar a emplear los elementos léxicos más transparentes como son los verbos cognitivos (creer, pensar, suponer, parecer...), para pasar después a los adverbios de probabilidad (quizá, tal vez, posiblemente, probablemente...). Los verbos modales (poder, deber (de), tener que, haber de...), en cambio, son los que mayor dificultad de comprensión y adquisición presentan por su ambigüedad e indeterminación.

Teniendo en cuenta esto, para la enseñanza de la expresión de la probabilidad el orden debería ser el siguiente:

a) Verbos cognitivos creer, pensar, suponery parecer en nivel A1.

b) Formas aproximativas, junto con los adverbios probablemente, posiblemente y seguramente (indicativo/aproximativo) en nivel A2+.

c) Mecanismos de modalidad externa que seleccionan estos dos modos en nivel B1. Ampliar los verbos cognitivos (imaginarse, figurarse), presentar otros adverbios como quizá, a lo mejor, igual, lo mismo, tal vez con indicativo o aproximativo, y una primera introducción sobre los verbos modales con valor epistémico (tener que, deber, deber de, poder).

d) Mecanismos de modalidad externa que seleccionan los tres modos en nivel B1+ (para comprobar que no es necesario el uso de subjuntivo). Las formas para expresar probabilidad ya vistas que permiten seleccionar indicativo, aproximativo y/o subjuntivo (creer que, suponer que, seguramente, probablemente, posiblemente, quizá, a lo mejor, igual, lo mismo, tal vez...).

e) Mecanismos de modalidad externa que seleccionan subjuntivo y verlos en contraste con el indicativo en nivel B2. Oraciones subordinadas sustantivas en función de sujeto (es posible que, es probable que, es dudoso que, no es seguro que, puede (ser) que...), así como mecanismos de probabilidad mediante sustantivos (tengo la duda de que/si, existe la posibilidad de que...). 


\subsection{Aplicación didáctica de los valores "lo conocido", "Io desconocido" y "lo virtual" en el aula de E/LE}

Para comprobar si estos nuevos valores aquí propuestos eran aplicables a los contextos de uso de la expresión de la probabilidad mediante mecanismos de modalidad interna y externa, se presentó una propuesta didáctica a estudiantes de español de nivel avanzado de Princeton University y de The University of Texas at Dallas durante los cursos académicos 2012-2013 y 2016-2017 respectivamente. Los resultados posteriormente obtenidos mostraron una considerable mejoría en la selección modal por parte de los estudiantes que recibieron tal instrucción.

Dicha propuesta presentaba la historia de una pareja cuyos amigos expresaban probabilidad sobre lo que podría estar pasando entre ellos. Aquí se muestran algunos de los ejemplos de dos de las secuencias -(20) y (21)- de la historia presentada y cómo los interpretaron los estudiantes:

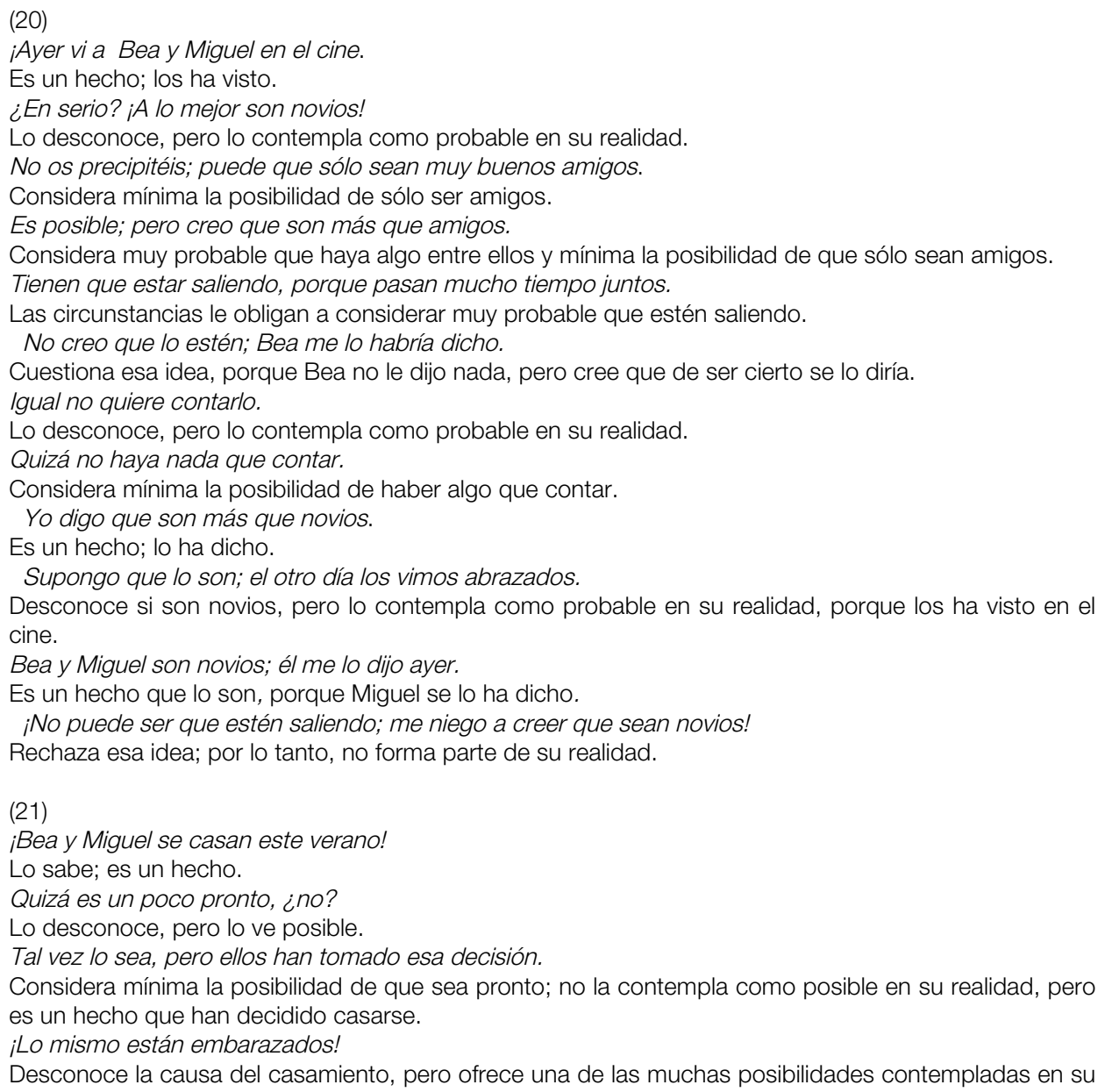


realidad.

Dudo mucho que sea por eso.

Cuestiona esa idea; no la contempla como posible en su realidad.

Si estuviera embarazada, me lo habría dicho, ¿no?

Considera mínima la posibilidad del embarazo, porque en ese caso, lo esperado era contárselo.

Puede ser que no quiera que la gente lo sepa.

Ofrece una posibilidad que ella misma no considera posible o no quiere comprometerse con lo dicho.

¡Sois unos cotillas! jSe casan porque se quieren!

Son hechos.

Tienes toda la razón.

Es un hecho.

¡No me puedo creer que se vayan a casar!

Esa idea no forma parte de su realidad; no la contempla como posible.

Pues ya tienen fecha.

Es un hecho.

\section{CONCLUSIONES}

Esta multiplicidad de mecanismos para expresar probabilidad parece ser la principal dificultad para el proceso de enseñanza/aprendizaje de dicha función comunicativa; sin embargo, encontramos otros obstáculos para su adquisición como son la tradicional interpretación del sistema verbal español, la selección modal y el valor pragmático que pueden llegar a adquirir dichos mecanismos formales.

En cuanto a los mecanismos de modalidad externa, muchos son los problemas planteados. En primer lugar, no todos los gramáticos le otorgan valor epistémico a las perífrasis obligativas y, con respecto a los adverbios de duda o hipótesis, solo se recogen quizá(s) o tal vez, olvidando algunos tan importantes y básicos como probablemente, posiblemente o seguramente. Además, sobre los enunciados de modalidad externa que emplean verbos cognitivos y modales, así como sustantivos y adjetivos casi no hay estudios y estos se limitan a clasificarlos según sus esquemas sintácticos de subordinación y qué modo selecciona cada una de estas unidades léxicas; si bien, hay intentos de clasificaciones semánticas que facilitarían la comprensión de su funcionamiento real que, desafortunadamente, se quedan en simples propuestas sin explicación alguna. Con todo, en las gramáticas de E/LE podemos ver una mayor flexibilidad a la hora de incluir muchos de estos mecanismos externos de claro y frecuente uso en la oralidad; sin embargo, no hay consenso a la hora de decidir cuáles son los que necesitarían los aprendientes, ya que no hay coincidencia en ninguna de ellas.

En torno a la interpretación del sistema verbal español, pocos son los que reconocen como modo independiente el modo aproximativo e intentan ofrecer nuevas descripciones más adecuadas para explicar estos fenómenos gramaticales en la clase de E/LE. Sin embargo, estas nuevas y revolucionarias propuestas no han llegado aún de forma definitiva a los manuales, métodos y gramáticas que se destinan a la enseñanza de E/LE. Así pues, el profesor de español como lengua extranjera es el que se encuentra más necesitado de ayuda teórica eficaz para afrontar los problemas que se presentan ante la categoría del modo en sus clases. 
Asimismo, otra cuestión de gran importancia es la enseñanza no solo del valor semántico que tienen las distintas formas de expresar la probabilidad en español, sino su valor pragmático, pues de esto depende que el aprendiente llegue a inferir el mensaje que su interlocutor quiere transmitirle. Así, expresiones como a lo mejor, igual o lo mismo, que suelen proponerse como mínima probabilidad, pueden funcionar como atenuantes pragmáticos de la responsabilidad pasando, por tanto, a expresar máxima probabilidad o, incluso, conocimiento de la veracidad o no de aquello sobre lo que el hablante hipotetiza, como es el caso de creer que, que además de expresar opinión puede tener un valor real de afirmación. Además, hay que tener en cuenta el hecho de que cada uno de los mecanismos formales para expresar probabilidad puede presentar una o varias marcas del rasgo [ \pm duda/probabilidad/posibilidad], dependiendo de la intención del hablante, de la interpretación subjetiva del interlocutor así como de otros componentes paralingüísticos o extralingüísticos.

El gran obstáculo para la enseñanza/aprendizaje de la expresión de la probabilidad es pues que tanto las gramáticas tradicionales como las de E/LE ofrecen descripciones por categorías gramaticales -a excepción de la Gramática Comunicativa de Matte Bon-, evitando pues su tratamiento como función comunicativa por la dificultad que esta supone. A pesar de la ambigüedad e indeterminación que presenta la mayoría de los mecanismos de modalidad interna y externa para la expresión de la probabilidad, es de imperiosa necesidad continuar el camino iniciado por Matte Bon para facilitar el proceso de enseñanza/aprendizaje y promover su comprensión y adquisición por parte de aprendientes de español L2/LE. Igualmente, el metalenguaje utilizado en la descripción del funcionamiento de dichos mecanismos demuestra incoherencias, de ahí que este no sea operativo para los estudiantes de español. Esto igualmente debería hacer reflexionar tanto a lingüistas como a profesores de E/LE sobre la necesidad de un cambio en la forma de describir el significado real de aquellos para poder, así, permitir al aprendiente alcanzar la competencia comunicativa en español deseada.

Está claro que la expresión de la probabilidad en español es una de las funciones comunicativas que más dificultades presenta en el proceso de enseñanza/aprendizaje, pero urge la necesidad de propuestas adecuadas, pues, aunque el aprendiente no emplee en su discurso muchos de los mecanismos formales para dicha función, necesita conocer el amplio abanico de recursos disponibles para poder interpretar correctamente el mensaje de su interlocutor.

Así pues, es necesario diseñar métodos didácticos que muestren el valor real de las distintas formas de expresión de probabilidad e intentar enseñarlas de forma gradual atendiendo a criterios semántico, sintáctico y pragmático, sin olvidar que estos están conectados.

\section{BIBLIOGRAFÍA}

ALARCOS LLORACH, E. (1994): Gramática de la lengua española, Madrid, Espasa Calpe.

BAÑÓN HERNÁNDEZ, A. M. (1999): "Apuntes para el análisis sintáctico- semántico de la locución a lo mejor en español hablado" en J. A. Samper Padilla (ed.), Actas del XI Congreso Internacional de la Asociación de Lingüística y Filología de la América Latina. Las Palmas de Gran Canaria 
(1996), v. 1, Universidad de Las Palmas de Gran Canaria, Servicio de Publicaciones, pp. 137-146.

BRIZ, A. (1995): "La atenuación en la conversación coloquial. Una categoría pragmática" en L. Cortés (ed.), El español coloquial. Actas del I Simposio sobre análisis del discurso oral, Almería, Servicio de Publicaciones, pp.103-122; ampliado en Briz (1998), cap. 4 y 6.

CARBONERO CANO, P. (1997): "Significado Modal y Significante modal". Introducción Teórica a la Pragmática Lingüística, Sevilla, Editorial Kronos. pp. 66-71.

CASTAÑEDA CASTRO, A. (2004a): "Implicaturas generalizadas de cantidad en el rendimiento de algunas formas y oposiciones del sistema verbal español". Language Design: Journal of Theoretical and Experimental Linguistics. $N^{\circ} 5$, 79-103.

(2004b): "Una visión cognitiva del sistema temporal y modal del verbo español". ELUA. Estudios de Lingüística. Anexo 2, pp. 55-71.

DEMONTE, V. (1977): La subordinación sustantiva, Madrid, Cátedra.

FERNÁNDEZ RAMÍREZ, S. (1986): Gramática española 4. El verbo y la oración. Volumen ordenado y completado por I. Bosque, Madrid, Arco/Libros.

GÓMEZ TORREGO, L. (1999): «Los verbos auxiliares. Las perífrasis verbales de infinitivo" en Bosque, I. y Demonte, V. (eds.) Gramática descriptiva de la lengua española, vol. 2, Madrid, Espasa Calpe, pp. 3323-3390.

LANGACKER, R. W. (1991): Foundations of Cognitive Grammar. Vol. II. Stanford, University Press.

LYONS, J. (1980) [1977]: Semántica, Barcelona, Teide.

MATTE BON, F. (1992): Gramática comunicativa del español. Vol. I y II. Barcelona, Difusión. (2006): "Maneras de hablar del futuro en español entre gramática y pragmática. Futuro, ir a + infinitivo y presente de indicativo: análisis, usos y valor profundo". Revista Electrónica de Didáctica en ELE, №. 6. [En línea]: http://www.mec.es /redele/revista6/ MatteBon.pdf

(2008): "El subjuntivo español como operador metalingüístico de gestión de la información". MarcoELE, revista de didáctica ELE. No. 6. [En línea]: http://marcoele.com/num/6/

02e3c09a6a11ee004/mattebon.pdf

REAL ACADEMIA ESPAÑOLA (2009): Nueva gramática de la lengua española. Madrid, Espasa Calpe.

REAL ESPINOSA, J.M. (2005): "Tiempo y aspecto verbal: marco teórico para la clase de E/LE". Marco ELE, Revista de Didáctica. №. 1. [En línea]: http://marcoele.com/

descargas/1/real_espinosa- tiempo-aspecto.pdf. (2009): "Gramática: la metáfora del espacio" en Marco ELE, Revista de Didáctica. N. 8. [En línea]: http://marcoele.com/descargas/8/jm.real _gramatica_la_metafora_del_espacio.pdf

RIDRUEJO, E. (1999): "Modo y modalidad. El modo en las subordinadas sustantivas". Gramática descriptiva de a lengua española. Vol. II. Las construcciones sintácticas fundamentales. Relaciones temporales, aspectuales y modales. Eds. Ignacio Bosque y Violeta Demonte. Madrid, Espasa Calpe, pp. 3209-3252.

RUIZ CAMPILLO, J.P. (1998): La enseñanza significativa del sistema verbal: un modelo operativo. Tesis doctoral. Universidad de Granada. Disponible en Biblioteca RedELE. NN. 1: 2004.

(2005): "El concepto de la nodeclaración como valor del subjuntivo. Protocolo de instrucción operativa de la selección modal en español". Actas del programa de formación para profesorado de ELE 2005-2006 del Instituto Cervantes de Munich. 2007. [En línea]: http://www.cervantesmuenchen.de/es/05_lehrerfortb/ Actas0506/3Jose Placido.pdf

STEPHANY , U. (1995): "Function and Form of the Modality in First and Second Language acquisition", en Giacalone Ramat \& Grocco Galeás (ed.) From pragmatics to syntax: Modality in second language acquisition, Tübingen, Gunter Narr Verlag, pp. 105-120.

ZAMORANO AGUILAR, A. (2001): Gramaticografía de los modos del verbo en español, Córdoba, Servicio de publicaciones Universidad de Córdoba. 